\title{
IDENTIFICATION AND ANALYSIS OF DRUG-RELATED PROBLEMS INCIDENCE AT HOSPITALIZED PATIENTS IN HAJI REGIONAL GENERAL HOSPITAL, MAKASSAR
}

\author{
MUHAMMAD ALDILA SATRIA ${ }^{1 *}$, SUDIBYO SUPARDI ${ }^{2}$ \\ ${ }^{1}$ Department of Pharmaceutical Science, Faculty of Pharmacy, University of Indonesia, Depok, West Java, Indonesia, ${ }^{2}$ Department of \\ Health Resources, National Institute of Health Research and Development, Indonesian Ministry of Health, Jakarta, Indonesia. Email: \\ muhammadaldilasatria@gmail.com
}

Received: 27 November 2020, Revised and Accepted: 19 January 2021

ABSTRACT

Objective: This study aims to identify inpatient medication problems and analyze the association between patient characteristics and the incidence of the drug-related problem (DRP) experienced by patients.

Methods: The cross-sectional study was conducted at Haji Regional General Hospital, Makassar, using medical record data for inpatients from January to February 2020. Data were collected from September to October 2020. A total of 247 inpatients were identified using the Indonesian version of the Pharmaceutical Care Network Europe.

Results: The most common DRP problem found is the effect of drug treatment not optimal (P1.2) by $35.76 \%$ and the most common cause found is no or incomplete drug treatment despite existing indication (C1.6) by $20.16 \%$. Bivariate analysis shows that age, length of stay, and the number of drugs received are significant different with the incidence of DRP in patients $(\mathrm{p}<0,01)$ respectively. Multivariate analysis using logistic regression shows that age, sex, and the number of drugs could significantly affect the incidence of $\mathrm{DRP}(\mathrm{p}<0.05)$ with the $\mathrm{r}$-square $\left(\mathrm{R}^{2}\right)$ of $21.6 \%$. According to this model, the largest odds ratio number and the most likely to experience DRP in a patient are age, the number of drugs, then gender (5,2; 4,6; and 2,3).

Conclusion: Age, length of stay, and the number of drugs received affect the DRP incidence in a patient, while gender together with age and the number of drugs affecting the incidence of DRP in a patient.

Keywords: Identification, Drug-related problem, Patient treatment.

(C) 2021 The Authors. Published by Innovare Academic Sciences Pvt Ltd. This is an open access article under the CC BY license (http://creativecommons.org/ licenses/by/4.0/) DOI: http://dx.doi.org/10.22159/ajpcr.2021v14i3.40391. Journal homepage: https://innovareacademics.in/journals/index.php/ajpcr

\section{INTRODUCTION}

Drug-related problem (DRP) is events or circumstances involving actual or potential drug therapy that can interfere with desired health outcomes [1]. DRP is often found and occurs in many communities, whether self-medication or consulting doctors [2] in primary, secondary, and tertiary health services. DRP occurs when inappropriate prescribing, ineffective, or unnecessary medication, underdose, overdose, the presence of unwanted drug events, patient non-compliance, and so on [3]. Lack of knowledge and patient noncompliance with medication use can be a significant factor in increasing the risk of DRPs [4]. This study is supported by the results of a study conducted by Al-Azzam in 2016, showing that $82.1 \%$ of chronic disease patients need education and counseling [3]. Moreover, since disease patients follow a complex treatment regimen, it was also identified as a critical factor in the increased risk of DRP in patients $[5,6]$.

In Indonesia, DRP can occur in several diseases, especially chronic diseases. Several studies conducted which identified DRP in patients with several chronic diseases such as kidney failure [7], diabetes mellitus [8], and heart failure [9] showed that the treatment carried out in the patient still has the potential for DRPs. The study results concluded that pharmacists' role in identifying, solving, and reducing the incidence of DRP in patients is needed [9]. It is then under the standard of pharmaceutical services in the hospital, as stated in the Minister of Health Regulation No. 72 of 2016, which states that identifying DRP is part of monitoring drug therapy activities carried out by pharmacists in hospitals.

Therefore, this study aims to identify the types of DRP in inpatients at the general hospital in Makassar, South Sulawesi. We also want to analyze the relationship between patient characteristics (age, gender, length of stay, and the number of drugs received) to the patients' DRP incidence.

\section{METHODS}

This study used a cross-sectional design. The study was conducted at the Haji General Hospital, Makassar, South Sulawesi with a data collection period from September to October 2020. This study has been examined and approved by the Health Research Ethics Committee of the Faculty of Medicine, University of Indonesia number KET-516/UN2. F1/ETIK/PPM.00.02.2020 with the protocol number 20-05-0529.

The research sample was inpatients, who visited the hospital during the period January-February 2020. Two hundred forty-seven patients were recruited in this study which fulfilled the requirements of the Slovin's formula and complied with the inclusion criteria as follows, that is, had been hospitalized and age $>18$ years. Meanwhile, the patient exclusion criteria were the patient's medical records, were not well documented.

We check for data completeness and compliance with the study inclusion criteria. They were followed by analyzing and identifying the DRP experienced by the patients while being treated with variables used in this study, that is, gender, age, length of stay, as well as the number of drugs received as independent variables and the number of DRP experienced by patients as the dependent variable. It also identifies the types of DRP experienced by patients by filling in the instrument's code on the DRP registration form using the Indonesian version of the Pharmaceutical Care Network Europe (PCNE). References such as Lexicomp, Medscape, IBM Micromedex, Pharmacotherapy Handbook, 
and journals related to a patient's disease are used to help researchers analyze DRPs.

The research data were analyzed using SPSS version 24.0 software. Univariate analysis was performed to determine demographics, type of disease, length of treatment, amount of drug, and amount of DRP experienced by patients. Bivariate analysis was performed to see the differences between groups on the independent variable with the DRP incidence in patients using Chi-square. Multivariate analysis was performed to determine the relationship between independent variables simultaneously on the DRP incidence in patients using logistic regression. $\mathrm{P}<0.05$ was set to indicate that the independent variable has a significant difference and relationship with the DRP incidence in patients.

\section{RESULTS}

A total of 247 patients were analyzed for DRP during their hospitalization retrospectively. Using medical record data for January-February 2020 was mostly dominated by women as much as $57.1 \%$ than men who were only $42.9 \%$. The patients' median age was 50 years, with a range of 18-88 years, and the median length of stay was 4 days with a range of 1-19 days. The demographics and patient characteristics are described in Table 1

Several drugs cause DRP. However, there are also symptoms experienced by patients but not given treatment. A total of 271 drugs caused DRP inpatients and 32 indications for untreated patients, as presented in Table 2:

Using the Indonesian version of the PCNE instrument, patients were counted on the number of DRP treated during hospitalization. The patients were qualitatively assigned the type of DRP with the help of the instrument. In total, there were 288 problems and 372 causes of DRP in patients. Patients experience DRP with a median of 1 problem and a range of 0-6 problems, which can be seen in full in Fig. 1.

The DRP identification results showed that the most common problems were drug therapy, which was not optimal (P1.2). The most common cause of DRP was that treatment was not given or incomplete even though there were indications (C1.6). In full, the problems and causes of DRP found in patients can be seen in Table 3.

Table 4 shows the analysis of patient characteristics on the incidence of DRP bivariate using Chi-square and Spearman correlation.

Multivariate analysis by logistic regression is using the backward method. With this method, the insignificant variables are excluded resulting in a model with a significant p-value. All independent variables were included in this analysis because they had a $\mathrm{p}<0.25$ [10]. The predictor used in this logistic regression is no sign of DRP inpatient as the dependent variable.

\section{DISCUSSION}

DRPs were identified based on the "problem" and "cause" domains on the PCNE instrument. The most "problem" experienced by the patients was the effect of drug treatment that is not optimal (P1.2) at 35.76\%. The primary "causes" of DRP was the no or incomplete drug treatment despite existing indication (C1.6), at $20.16 \%$. This result is not much different from the research reported by Herman and Sari in 2012 and Saldanha et al. in 2020. In the "problem" domain, we found that the most frequent issue occurs the suboptimal therapeutic effect experienced by $20.7 \%$ of the total DRP [11] and has cumulative incidence at $9.21 \%$ [12].

Meanwhile, in the "cause" domain, our findings are quite different from other studies. As conducted by Abunahlah et al., it was found that the most common cause of DRP in patients was the presence of inappropriate drug combinations [13]. In contrast to Herman and Sari and Saldanha et al., they reported that the treatment duration is too
Table 1: Demographics and clinical characteristics of inpatients at Haji General Hospital, Makassar during the period January-February $2020(n=247)$

\begin{tabular}{llll}
\hline Variable & $\mathbf{n = 2 4 7}$ & $\mathbf{\%}$ & Median (Min-Max) \\
\hline $\begin{array}{l}\text { Gender } \\
\quad \text { Men }\end{array}$ & 106 & 42.9 & - \\
$\quad$ Women & 141 & 57.1 & \\
Age & & & $50(18-88)$ \\
$\quad$ 18-59 years & 164 & 66.4 & \\
$\quad$ Greater than or equal to & 83 & 33.6 & \\
$\quad$ 60 years & & & \\
$\quad$ Length of stay & & & $4(1-19)$ \\
$\quad$ Less than or equal to days & 119 & 48.2 & \\
$\quad$ Greater than 3 days & 128 & 51.8 & \\
$\quad$ Number of drugs received & & & $6(2-20)$ \\
$\quad$ Less than 5 drugs & 67 & 27.1 & \\
$\quad \begin{array}{l}\text { Greater than or equal to } \\
\quad 180\end{array}$ & 72.9 & \\
$\quad$ drugs & & & \\
\hline
\end{tabular}

Table 2: Types of drugs that cause drug-related problem in inpatients at the Haji General Hospital, Makassar for the period January-February 2020

\begin{tabular}{lll}
\hline Drug therapy class & Number & Percentage \\
\hline Antibiotic & 70 & 23.1 \\
NSAID & 38 & 12.5 \\
Steroids & 23 & 7.6 \\
Antihyperglycemic & 20 & 6.6 \\
Gastroenterology drugs & 19 & 6.3 \\
Antihypertension & 17 & 5.6 \\
Antipyretics & 16 & 5.3 \\
Antihistamines & 11 & 3.6 \\
Antiemetics & 8 & 2.6 \\
Antiepilepsy & 6 & 2 \\
Antihyperlipidemic & 6 & 2 \\
Others & 19 & 12.2 \\
Untreated indication & 32 & 10.6 \\
Total & 303 & 100 \\
\hline
\end{tabular}

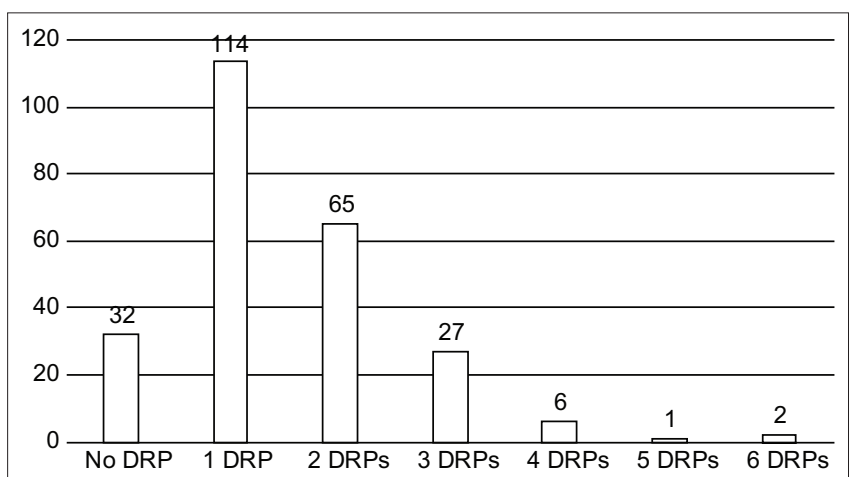

Fig. 1: Number of DRP experienced per patient during hospitalization ( $n=247)$; DRP: Drug-related problem

long as the most cause issue of DRP in patients [11,12]. Thus, it can be concluded that drug selection is still the most common cause of inpatient care at the hospital, which agrees with studies reported.

Based on the Chi-square results, the effect of the gender variable on the number of DRP has a $\mathrm{p}=0.075$, which indicates that between the sex groups there is no significant difference in the increase in the number of MTO in patients. Meanwhile, the variable age, length of stay, and the amount of drug to the amount of DRP had a $p<0.05$. This shows that between groups in these three variables significantly increases the number of MTO in patients. Research conducted by Lenssen et al. and Modesto et al. showed a significant effect on age and the number of 
Table 3: The types of problems and causes of drug-related problem identified in inpatients at Haji General Hospital, Makassar

\begin{tabular}{clc}
\hline Primary domain & Secondary domain & Quantity (\%) \\
\hline PROBLEM & & $25(8.68)$ \\
P1 & P1.1 No effect of drug treatment & $103(35.76)$ \\
& P1.2 Effect of drug treatment not optimal & $64(22.22)$ \\
P2 & P1.3 Untreated symptoms or indication & $45(15.62)$ \\
P3 & P2.1 Adverse drug event (possibly) occurring & $50(17.36)$ \\
TOTAL & P3.2 Unnecessary drug-treatment & $288(100)$ \\
CAUSES & & \\
C1 & C1.1 Inappropriate drug according to guidelines/formulary & $11(2.95)$ \\
& C1.2 Inappropriate drug (within guidelines but otherwise contra-indicated) & $12(3.22)$ \\
& C1.3 No indication for the drug & $49(13.17)$ \\
& C1.4 Inappropriate combination of drugs, or drugs and herbal medications, or drugs and dietary supplements & $50(13.44)$ \\
& C1.5 Inappropriate duplication of a therapeutic group or active ingredient & $21(5.64)$ \\
C2 & C1.6 No or incomplete drug treatment despite an existing indication & $75(20.16)$ \\
C3 & C1.7 Too many drugs prescribed for an indication & $5(1.34)$ \\
& C2.1 Inappropriate drug form (for this patient) & $2(0.53)$ \\
& C3.1 Drug dose too low & $5(1.34)$ \\
C4 & C3.2 Drug dose too high & $7(1.88)$ \\
C6 & C3.3 Dosage regimen not frequent enough & $15(4.03)$ \\
& C3.4 Dosage regimen too frequent & $2(0.53)$ \\
& C4.1 Duration of treatment too short & $38(10.21)$ \\
C9 & C6.1 Inappropriate timing of administration or dosing intervals & $42(11.29)$ \\
& C6.2 Drug under-administered & $13(3.49)$ \\
TOTAL & C6.4 Drug not administered at all & $8(2.15)$
\end{tabular}

Table 4: Chi-square result in inpatient against the DRP incidence

\begin{tabular}{|c|c|c|c|c|c|}
\hline \multirow[t]{2}{*}{ Variables } & \multicolumn{2}{|c|}{ No DRP presence ${ }^{+}$} & \multicolumn{2}{|c|}{ DRP presence ${ }^{+}$} & \multirow[t]{2}{*}{ p-value } \\
\hline & $\mathbf{n}$ & $\%$ & $\mathbf{n}$ & $\%$ & \\
\hline \multicolumn{6}{|l|}{ Sex } \\
\hline Men & 18 & 17.0 & 88 & 83.0 & 0.075 \\
\hline Women & 14 & 9.9 & 127 & 90.0 & \\
\hline \multicolumn{6}{|l|}{ Age } \\
\hline $18-59$ years & 29 & 17.7 & 135 & 82.3 & $0.001^{* *}$ \\
\hline Greater than or equal to 60 years & 3 & 3.6 & 80 & 96.4 & \\
\hline \multicolumn{6}{|l|}{ Length of stay } \\
\hline Less than or equal to 3 days & 22 & 18.5 & 97 & 81.5 & $0.01^{*}$ \\
\hline Greater than 3 days & 10 & 7.8 & 118 & 92.2 & \\
\hline \multicolumn{6}{|l|}{ Number of drugs received } \\
\hline Less than 5 drugs & 19 & 28.3 & 48 & 71.7 & $<0.01^{* *}$ \\
\hline Greater than or equal to 5 drugs & 13 & 7.2 & 167 & 92.8 & \\
\hline Total & 32 & 12.9 & 215 & 87.1 & \\
\hline
\end{tabular}

*There is a significant difference at $\mathrm{p}<0.05,{ }^{* *}$ There is a significant difference at $\mathrm{p}<0.01,{ }^{+} \mathrm{DRP}$ : Drug-related problem

Table 5: Multivariate analysis results using logistic regression

\begin{tabular}{|c|c|c|c|c|c|c|c|}
\hline \multirow[t]{2}{*}{ Variables } & & \multirow[t]{2}{*}{ Coefficient } & \multirow[t]{2}{*}{$\mathbf{p}$} & \multirow[t]{2}{*}{ OR } & \multicolumn{2}{|c|}{ CI 95\% } & \multirow[t]{2}{*}{$\mathbf{R}^{2}$} \\
\hline & & & & & Min & Max & \\
\hline \multirow[t]{4}{*}{ Model 1} & Men & 0.824 & $0.046^{*}$ & 2.28 & 1.01 & 5.13 & 0.216 \\
\hline & Less than or equal to 3 days & 0.440 & $0.322 *$ & 1.55 & 0.65 & 3.71 & \\
\hline & Less than 5 drugs & 1.411 & $0.001^{* *}$ & 4.09 & 1.77 & 9.47 & \\
\hline & Constant & -4.177 & $0.001^{* *}$ & 0.015 & & & \\
\hline \multirow[t]{4}{*}{ Model 2} & Men & 0.835 & $0.043^{*}$ & 2.305 & 1.03 & 5.18 & 0.209 \\
\hline & Less than or equal to 3 days & 1.651 & $0.01^{*}$ & 5.213 & 1.48 & 18.30 & \\
\hline & Less than 5 drugs & 1.539 & $<0.01^{* *}$ & 4.661 & 2.08 & 10.42 & \\
\hline & Constant & $-3,816$ & $0.002^{* *}$ & 0.022 & & & \\
\hline
\end{tabular}

*There is a significant difference at $\mathrm{p}<0.05,{ }^{* *}$ There is a significant difference at $\mathrm{p}<0.01$

drugs received with $\mathrm{p}<0.01$ [14]. In contrast to this study, the findings in the study of Modesto et al. did not show a significant difference in length of stay $(\mathrm{p}<0.01$ vs. 0.613$)$ [15].
Multivariate analysis showed that in the second model, which is the final model. When the patient is men, stay in the hospital for 3 days or less, and receive $<5$ drugs could significantly influence the incidence of 
DRP in patients by $20.9 \%\left(\mathrm{R}^{2}=0.209\right)$ simultaneously. The variables that have a strong influence when viewed from the odds ratio (OR) are age, followed by the number of drugs, and gender. The OR value especially for the number of drugs received in this study was higher than that of Peterson and Gustafsson's study, 5.08 versus 1.478 [16]

Researchers' main limitation is the identification process of DRP which is carried out only relies on secondary data from medical records so that raises the potential for bias. This study only identifies the "problem" and "cause" domains without identifying any other domains; this is because this study was conducted retrospectively without direct follow-up to patients. Nevertheless, this study emphasizes the importance of pharmacist records in integrated patient development records as part of pharmacist control and minimizing DRP that may be experienced by patients.

\section{CONCLUSION}

This study's results indicate that the most problems of the inpatient were the effect of drug treatment not optimal (P1.2) and the most common cause is that the treatment was no or incomplete drug treatment despite existing indication (C1.6). The bivariate analysis shows that patient's age, length of stay, and the number of drugs received are affect the patient's risk of developing DRP $(\mathrm{p}<0.05)$ significantly. However, the patient's gender, length of stay, and the number of drugs received in the multivariate analysis show a significant difference in DRP incidence experienced by patients $(\mathrm{p}<0.01)$ simultaneously. Thus, these factors influence patients to experience DRP while being treated in the hospital.

\section{AUTHORS' CONTRIBUTION}

Muhammad Aldila Satria as the first author to conduct the research (data collection) with the help of Sudibyo Supardi to the concept of the matrix and analysis of this research.

\section{CONFLICTS OF INTEREST}

All authors stated no potential conflict of interest with research, authorship, and publication of this article.

\section{AUTHORS' FUNDING}

Any grant sources did not fund this research.

\section{REFERENCES}

1. van Mil JW, Westerlund LO, Hersberger KE, Schaefer MA. Drug-related problem classification systems. Ann Pharmacother 2004;38:859-67.

2. Rikomah SE. Farmasi Klinik. Yogyakarta: Deepublish Publisher; 2016.

3. Al-Azzam SI, Alzoubi KH, Alefan Q, Alzayadeen RN. Evaluation of the types and frequency of DRP and the association with gender in patients with chronic diseases attending a primary health care center in Jordan. Int Health 2016;8:423-6.

4. Abu Farha RK, Mukattash TL, Qudah R, Alkhalaileh W, Alsaffar S. DRP and health-related quality of life in outpatients with Type 2 diabetes: A crosssectional study from Jordan. J Pharm Health Serv Res 2019;10:303-9.

5. Hsu KL, Fink JC, Ginsberg JS, Yoffe M, Zhan M, Fink W, et al. Selfreported medication adherence and adverse patient safety events in CKD. Am J Kidney Dis 2015;66:621-9.

6. Kovačević SV, Miljković B, Ćulafić M, Kovačević M, Golubović B, Jovanović M, et al. Evaluation of DRPin older polypharmacy primary care patients. J Eval Clin Pract 2017;23:860-5.

7. Ramadaniati HU, Anggriani Y, Wowor VM, Rianti A. DRPin chronic kidneys disease patients in an Indonesian hospital: Do the problems really matter? Int J Pharm Pharm Sci 2016;8:298-302

8. Zazuli Z, Rohaya A, Adnyana KI. DRPin Type 2 diabetic patients with hypertension: A prospective study. Int J Green Pharm 2017;11:298-304.

9. Sagita VA, Bahtiar A, Andrajati R. Evaluation of a clinical pharmacist intervention on clinical and DRP among coronary heart disease inpatients: A pre-experimental prospective study at a general hospital in Indonesia. Sultan Qaboos Univ Med J 2018;18:e81-7.

10. Dahlan, S. Statistik Untuk Kedokteran dan Kesehatan. $6^{\text {th }}$ ed. Jakarta: Epidemiologi Indonesia; 2014.

11. Herman MJ, Sari ID. Analisis MTO di lima rumah sakit tahun 2010. J Ilmu Kefarmasian Indones 2012;10:163-9.

12. Saldanha V, Martins RR, Lima SI, de Araujo IB, Oliveira AG. Incidence, types and acceptability of pharmaceutical interventions about drug related problems in a general hospital: an open prospective cohort. BMJ Open 2020;10:1-8.

13. Abunahlah N, Elawaisi A, Velibeyoglu FM, Sancar M. Drug related problems identified by clinical pharmacist at the internal medicine ward in Turkey. Int J Clin Pharm 2018;40:360-7.

14. Lenssen R, Heidenreich A, Schulz JB, Trautwein C, Fitzner C, Jaehde U, et al. Analysis of DRPin three departments of a German University hospital. Int J Clin Pharm 2016;38:119-26.

15. Modesto AC, Ribeiro AM, Pereira JL, Silva LT, Provin MP, Ferreira PS, et al. Evaluation of a method for DRP identification and classification in hospital setting: Applicability and reliability. Int J Clin Pharm 2020;42:193-200.

16. Peterson C, Gustafsson M. Characterisation of DRP and Associated factors at a clinical pharmacist service-naïve hospital in Northern Sweden. Drugs Real World Outcomes 2017;4:97-107. 